International Research Journal of Management, IT \& Social Sciences
Available online at https://sloap.org/journals/index.php/irjmis/
Vol. 6 No. 6, November 2019, pages: 128 134
ISSN: 2395-7492
https://doi.org/10.21744/irjmis.v6n6.784

\title{
Psychological Actions for Tactical Thinking Development on Solving Tasks in School Volleyball
}

\author{
Yanelis Quesada Hidalgo ${ }^{a}$ \\ José Ignacio Ruiz Sánchez ${ }^{\text {b }}$ \\ Taimí Wambrug Callejas ${ }^{c}$ \\ Hilda Rosa Rabilero Sabates ${ }^{\mathrm{d}}$
}

Article history:

Received: 27 July 2019

Accepted: 30 September 2019

Published: 28 October 2019

\author{
Keywords: \\ homework solution; \\ psychological intervention; \\ school volleyball; \\ tactical thinking; \\ training and competition;
}

\begin{abstract}
The research aimed to design a proposal for psychological intervention actions that enable the development of tactical thinking in the solution of training and competition tasks, in school volleyball players of the EIDE "Cerro Pelado" of Camaguey For this purpose, it was based on the diagnosis of the individual features of consecutive thinking, flexibility, and speed, as well as the analysis of the decision-making process, in which the analysis and perception of the current defensive tactical game situation are related, with similar previous experiences to adopt the most appropriate solution, in athletes.
\end{abstract}

2395-7492@ Copyright 2019. The Author. This is an open-access article under the CC BY-SA license (https://creativecommons.org/licenses/by-sa/4.0/) All rights reserved.

\section{Author correspondence: \\ Yanelis Quesada Hidalgo, \\ Center of Sports Medicine of Camagüey, Camaguey, Cuba. \\ Email address: jnely@nauta.cu}

\section{Introduction}

Volleyball is a game that has a tactical purpose, hence, it is necessary to develop a large arsenal of technical-tactical skills with the use of tactical thinking to solve the variable tasks imposed by the game (Navelo, 2004). This is a very complex process that aims to realize the situation in which the player is, but also the execution and selection of the response that he deems most appropriate for the resolution.

Therefore, use a set of psychological intervention actions so that the volleyball player knows what needs to be done; what to decide; How to do it and know how to do it well, can lead to training creative, intelligent, decisive players, who accurately reflect what happens during the competition. This process must be worked on considering the psychological preparation in conjunction with the tactical preparation, the backbone of the coach's aspirations, from then on, to direct attention to the psychological needs that athletes require.

${ }^{a}$ Center of Sports Medicine of Camagüey, Camaguey, Cuba

${ }^{\mathrm{b}}$ Universidad Ignacio Agramante Loynaz, Camaguey, Cuba

${ }^{\mathrm{c}}$ Universidad Ignacio Agramante Loynaz, Camaguey, Cuba

${ }^{\mathrm{d}}$ Universidad de Oriente, Santiago de Cuba, Cuba 
It becomes evident in school volleyballists a general problem related to the confrontation and resolution of situations and defensive tactical problems that occur during the game, which are presented as inadequacies in the development of tactical thinking in the solution of tasks during training and competition in Volleyball players in the 13-15 year school category of the "EIDE" Cerro Pelado "in Camagüey. For the foregoing the scientific problem is formulated as follows: How to contribute to the development of tactical thinking in the solution of tasks during training and competition in volleyball players school category 13-15 years of the "EIDE" Cerro Pelado "From Camaguey?

The objective of the research is to design a proposal of psychological intervention actions that enable the development of tactical thinking in the solution of tasks during training and competition in volleyball players category 13-15 years of the EIDE “Cerro Pelado" of Camagüey.

\section{Materials and Methods}

The sample consists of 12 Camagueian male volleyball players of the school category, belonging to the EIDE "Cerro Pelado". The sample $(n=12)$ has been selected through a non-probabilistic, intentional sampling. It is composed of the 12 volleyball players that make up the regular team. The age of volleyball players ranges between 13 and 15 years.

Description of the methods and techniques

The methods used to carry out the research were determined by the objectives and tasks envisaged. From the theoretical level, the following were used:

- Analytical-synthetic: It is of vital utility both in the realization of the theoretical framework of reference and in the analysis of data products of the research itself, in order to refer to the most significant elements both in the diagnostic period, of elaboration of the methodology, as in the evaluation of the proposal.

Inductive-deductive: it is based on the study of tactical thinking to emphasize resources and defensive tactical actions in volleyball, and at the same time ensure that the conclusions that are reached enrich the theoretical elements that are known about this process.

In the present investigation, measurement (using the Test to determine the consecutiveness, flexibility, and speed of thinking in the solution of tasks, proposed by Sánchez \& González (2005), was used as empirical methods, and the interview technique, (semi-structured interview).

The semi-structured coach interview was aimed at obtaining information on the elements that indicate the development of tactical thinking in solving tasks in defensive actions, according to their criteria. It consists of ten reference points or questions that collect information on the elements of the perceptual environment in which the volleyball player must fix his attention and his expression in logical order, for the execution of the reception of the serve/block/ field defense; on the selection, programming and evaluation of the effectiveness in the execution of these actions, as well as the game and defense system used by the team (Singh \& Parmar, 2016).

The semi-structured interview with the athlete aimed to know the processes used according to the following categories, perceptual elements of the environment: those aspects of the game situation in which the player fixes his attention before making a decision; decision making, technical-tactical action options, changes in decision making and evaluation of the decision taken and executed. It consists of conducting a stimulated memory interview, evoking a memory of the previous game. It was performed during the diagnostic stage, individually, before starting the training session.

It consists of five reference points or questions, which collect the following information; what is paid attention to at the time of receiving the service / blocking / defending the field; specific aspects that you want to specify about these defensive tactical actions; tactical technical action options that you value; main reasons why you decide to receive the serve/block/ defend; if there are changes between what is decided and executed, as well as the assessment of the tactical effectiveness of the action and the possible changes it must make.

In the test to determine the consecutiveness, flexibility, and speed of thinking in the solution of tasks. The subject must perform two tasks. In the first task, the subjects under study are shown several sheets of figures related to the execution of different exercises, so that they determine the missing figure. In the second task, they must lengthen each of the rows that appear on the sheet, finding the missing figure. Both solutions must be found through the search for a certain regularity.

In each task, the researcher, after giving the subject to the subjects, must control the time invested by them to find the solution. This allows determining the speed of thought. Once each task is completed, the following questions should be asked for each subject: What is the regularity that allowed you to reach the given solution? Did you maintain or change the solution path? These questions will provide information about consecutive and flexible thinking.

Hidalgo, Y. Q., Sánchez, J. I. R., Callejas, T. W., \& Sabates, H. R. R. (2019). Psychological actions for tactical thinking development on solving tasks in school volleyball. International Research Journal of Management, IT and Social Sciences, 6(6), 128-134. https://doi.org/10.21744/irjmis.v6n6.784 
Statistical methods: Statistical methods allowed to assess the results in each phase of the investigation. For the analysis of the results, the descriptive statistics were applied, using the median and the mode as central tendency measures. Additionally, empirical distributions of absolute and relative frequencies were used for the qualitative analysis of the variables. Statistical processing was performed using the statistical package SPSS 22.0 for Windows.

For the realization of this research, the following variables were taken into consideration as relevant variables:

The dependent variable tactical thinking in the solution of tasks during training and competition in Volleyball players category 13-15 years, is operationalized establishing two dimensions; an individual dimension that has as indicators the individual traits of thinking in the solution of tasks, consecutiveness, flexibility and speed and a cognitive one, with the following indicators; analysis and perception of the game situation; decision making and evaluation of the decision taken and executed.

The independent variable of psychological intervention actions is defined as training aimed at the development of skills, comprehension and perceptual; decisional; for the programming of actions; for the valuation and control, based on the individual features of the consecutive thought, flexibility, and speed of the volleyball players.

\section{Results and Discussions}

The semi-structured interview with coach of the category allowed to know the elements that should be perceived when receiving the service expressed in logical order, these are: the type of service, the power of the service and the direction; the criteria on the effectiveness of receiving the service, when all planned combinations can be established; elements that are taken into account to perform an individual, double lock and for its effectiveness, such as the height and direction of the serve; the height of the ball, taking into account the other partner who blocks and the position of the auctioneer, which becomes effective when the ball is won, or the offensive of the opponent is prevented and the team scores or scores the point

They are considered by the coach as elements that must be perceived, to perform a good field defense, the concentration of attention, the position of the ball, the direction of the ball, the characteristics of the auctioneer. This action is effective when the ball is won and the team scores or scores the point, when the offensive of the opponent on their own court is prevented. They are identified as, game system and team defense; $6-2$ with 6 late and 4-2; 5-1; 6-2, respectively. The coach refers to the difficulties of school volleyball players to identify the elements mentioned above in the analysis and perception of the different game situations, as well as, for the execution, assessment, and control of these defensive tactical actions and their successful performance in training and competences

The semi-structured interview with the athlete (school volleyball player) shows, as regards the perceptual elements of the environment, those aspects of the game situation in which the player fixes his attention on defensive actions. In relation to the reception of the service, $81 \%$ refer to focus only on the type of service, not to mention the information related to the server and the position he has on the court; the power of the serve and its direction.

With respect to the blockade, none of the elements on which the player must pay attention, such as the type of block, the ball, the position of the auctioneer's hand, the height and the direction, are mentioned or identified by the volleyball players of the serve. A similar situation occurs with the field defense, where they are not noticed as aspects on which attention should be fixed, the position occupied on the court, the good concentration; the position of the ball; the direction of the ball and the characteristics of the auctioneer.

With regard to decision-making, as regards the options of defensive technical-tactical actions understudy, volleyball players generally value the performance of the action of receiving, blocking or defending, but are not able to refer or include, varied possibilities of action that would be executed according to the elements of the environment perceived in-game situations, to finally choose one of the alternatives proposed for its realization. Among the main reasons why they decide to receive the serve/block/defend; that is, execute the defensive elements, meet, score or score points (8), $72 \%$; receive well (3), $27 \%$; and not lose (1), $9 \%$, so it can be seen that there is no reference to specific indicators of efficient performance in each of these actions.

Regarding the assessment of whether changes appear between what is decided and executed, by school volleyball players, in (8) of them, (72\%), there are no changes while, in (4) 36\%, if changes occur, this implies specifying and identifying in each of the athletes, which are those situations of play in defensive tactical actions, where the coincidence or not of the decision taken initially and the execution carried out afterward is reflected.

When analyzing the evaluation of the decision made and executed by the volleyball players, with the completion of a personal balance on the effectiveness of the action that the player finally executed, criteria related to the quality of the execution are not issued, indicators of good performance, such as, the establishment of all planned combinations, 
(effectiveness of receiving the serve); win the ball, prevent the opponent's offense and the team scores or scores the point (blocking effectiveness); to prevent the offensive of the opponent in own court (effectiveness of the field defense), and it is not necessary either to change according to the executions in the different situations of game, in defensive tactical actions.

In the test to determine the consecutiveness, flexibility, and speed of thinking in the solution of tasks. It can be seen in task 1 , in relation to the information about the consecutive and flexible thinking, that only one of the volleyball players, (9\%) (subject 1), identifies all the elements of regularity; the position of the arms, the geometric figure of the saya and the type of shoes he wears, and he maintains the solution path to choose correctly the missing figure, number 6. On the other hand, three of the volleyball players (27\%) (subjects 3,6,10), identify two of the elements of regularity; the position of the arms and the geometric figure of the saya, and they maintain this solution path to correctly choose the missing figure.

When controlling the time invested by volleyball players to find the solution, of the four athletes who identify the regularity and the right figure, the one who manifests the highest speed of thought, is subject 6 , by investing only 00 : $40 \mathrm{~s}$ to perform the task, in a second-order, subject 3, with 1: $32 \mathrm{~s}$, subsequently, subject 1 with 1: $57 \mathrm{~s}$, and, finally, subject 10 with 2: $14 \mathrm{~s}$. The rest of the team's volleyball players do not identify regularity, therefore, they do not find the correct missing figure, which limits them to find the right solution to the task.

With regard to task 2, in relation to information about the consecutive and flexible thinking, two volleyball players (27\%) (subjects 1 and 10), find the right solution, by completing the correct figure and identifying the regularity in each row of the proposed task, by changing the solution paths and finding the right one to solve the problem. Also, three of them $(27 \%$ ) (subjects 6, 7 and 11) manage to complete with the correct figure and identify the regularity in the majority (three) of the rows of the proposed task, with the change of solution paths and finding the most appropriate to solve the problem.

The time invested by volleyball players who found the right solutions, was greater in the fourth row, in each of them, considered this, the most complex to find regularity, according to the criteria of the athletes. It is important to note that none of the respondents was able to perform the task independently without the help or guidance of the investigator, required at least a second explanation, after giving the general instructions, that would require them to pay attention or allow them to perceive, which were the mathematical operations that had to be carried out as regularity, to arrive at the final and correct figure of the row.

The previous results reflect the characteristics of the development of the individual traits of thought, consecutive, flexible and fast in the volleyball players of the sample, expressed in the difficulties to achieve a logical order of the acts of thought, in the analysis of a certain situation in system form, without deviating, without randomly jumping from one idea to another (consecutive); in the impossibility, sometimes, to appreciate if it is necessary to maintain or change the means or ways of solution when they are inadequate and find new solutions that demand a new approach to the problem (flexibility), as well as, the need to improve the capacity to be able to give the right solution in minimum time, that is, greater speed of thought (speed)..

\section{Psychological intervention actions for the development of tactical thinking in the solution of tasks in school volleyball players 15-16 years of Camagüey}

The proposed intervention action group consists of ten activities aimed at both individual and group training of tactical thinking in the solution of tasks. These activities were taken from authors such as Del Monte (1998, 2005); Locke \& Latham (1985; cited in Gonzalez, 2003); Iglesias et al., (2002, 2003); González (2003); Sánchez (2005), Cañizares (2009); Sainz de la Torre (2010); and Soler (2016).

Objective: To raise the level of development of tactical thinking in the solution of tasks, in athletes of the male volleyball school team of Camagüey, category 15-16

Organization

The application of the actions has been distributed in ten weeks covering three fundamental phases, (Weinberg \& Gould, 2013; cited in Sarmiento, 2011). Educational phase: the means, methods to be used for the development of tactical thinking in the solution of tasks, their benefits, and procedures, as well as the framing of the sessions are presented Subsequently, an adequate level of commitment and permanence of all participants is established. (First and second week)

Acquisition phase: the dynamic is focused on the strategies and techniques necessary for the development of tactical thinking in the solution of tasks. This moment is divided into individual and group training sessions. The pertinent

Hidalgo, Y. Q., Sánchez, J. I. R., Callejas, T. W., \& Sabates, H. R. R. (2019). Psychological actions for tactical thinking development on solving tasks in school volleyball. International Research Journal of Management, IT and Social Sciences, 6(6), 128-134. https://doi.org/10.21744/irjmis.v6n6.784 
adaptations to the proposed techniques are made, adapting them to the circumstances and particularities of the sport and of each subject. (From the third to seventh week)

Practical phase: its fundamental objectives are to automate the skills worked in relation to the process, systematically integrate them into their executions and apply them to the competencies in which they participate. (from eighth to tenth week). Several techniques are performed in a group framework and others are individual; in both cases they are carried out in training sessions with their characteristic environment.

Assuming the statement by Rodionov (1990), (cited in Sainz, 2010), in relation to the effectiveness of the tactical resolution determined by the level of perceptual, intellectual and psychomotor qualities; and the foundations of Temprado (1991), which establish a parallel between "tactical thinking" and "knowing how to decide" or operational thinking that involves several skills, as well as, the established categories, in the decision-making model proposed by Iglesias et al., (2002); The actions were organized for the development of 4 fundamental skills that should be promoted in athletes for the development of tactical thinking in the solution of tasks, they are:

a) Understanding and perceptual skills: (Know what is to be done); know the aspects of the game situation in which the player fixes his attention, which leads to setting the action objectives to solve it.

b) Decision skills: (Know what to decide); selection and assessment of the possibilities of technical-tactical action options that the player must execute, and his final choice.

c) Skills for programming actions: (Knowing how to do it) identification and organization in a suitable procedure the sub-objectives that allow solving the problem.

d) Skills for the evaluation and control of the execution: (Knowing how to do it) Personal balance on the coincidence of the decision taken initially and the execution carried out later; control and effectiveness of the required action.

In this sense, the techniques were distributed in the following groups.

Group 1: Exercises for the development of the perception of information and the concentration of attention

Technical:

- Ideomotor training (Sainz de la Torre, 2010)

- The combined technique of cognitive processes (Del Monte, 1998)

- Verbalization and description of the essential points and gestures that precede the actions of the opposite, for the efficient execution of defensive actions.

Group 2: Exercises for decision making and evaluation.

The verbal or written description of the content of the models of the different defensive moves, to see if they are clear on the mental plane.

- Gradual education of the mental solution: request the answer to a given tactical defensive situation presented and the athlete is given the possibility of giving him the solution, at different times up to the minimum time, according to his models.

- Observation of images of defensive tactical situations for the subsequent analysis of the possibilities of action that the player valued to execute, the one he chose, for its realization and of the coincidence or not of the decision taken initially and the execution made afterward.

Group 3: Exercises for the clarification of objectives

Chats-debates: they constitute support techniques through which the athlete is offered all the necessary information for the knowledge of the process in question.

- Establishments of performance objectives and goals in partial tasks.

- Use of personal diary.

Group 4: Exercises for the assessment, control, and effectiveness of the required action

- Techniques of group dynamics of analysis and discussion for the critical analysis of one's own participation and that of the opposite; of tactical combinations of stronger teams and situations of defensive tactical tasks and their solution. 


\section{Conclusion}

The solution to situations is considered as an activity and thought process, with a dynamic nature, given both, by the peculiarities of the situations and those of the athlete, which gives a motor solution. The organic relationship between problem-solving and thinking constitutes the basis and starting point of the tactical training of the athlete in the teaching-learning process.

Difficulties are manifested in school volleyball players to achieve a logical order in the analysis of defensive tactics and knowledge that allow them to quickly identify the objectives, relevant means; those that refer to the possibilities of selection, and those that concern the implementation of the response programs in minimum time. The proposed intervention action group consists of ten activities aimed at training four fundamental skills, based on the results of the diagnosis, both individual and group of tactical thinking in the solution of tasks.

\section{Conflict of interest statement}

The authors declared that they have no competing interests.

Statement of authorship

The authors have a responsibility for the conception and design of the study. The authors have approved the final article.

\section{Acknowledgments}

We thank you for the editorial team of accepting the present paper.

Hidalgo, Y. Q., Sánchez, J. I. R., Callejas, T. W., \& Sabates, H. R. R. (2019). Psychological actions for tactical thinking development on solving tasks in school volleyball. International Research Journal of Management, IT and Social Sciences, 6(6), 128-134. https://doi.org/10.21744/irjmis.v6n6.784 


\section{References}

Cañizares M. (2009). Psychology in physical activity. Its application in sports, physical education, recreation and rehabilitation. Havana City: Editorial Sports.

Del Monte, L. M. (1998). Mimeographed lecture "A look at judokas from the psychological point of view". Retrieved on June 25, 2014 from Judo Website, INDER, Havana.

Del Monte, U. (2005). Swelling of hepatocytes injured by oxidative stress suggests pathological changes related to macromolecular crowding. Medical hypotheses, 64(4), 818-825. https://doi.org/10.1016/j.mehy.2004.08.028

González, A. (2003). Attention and Sports Performance. EduPsyKhé. Journal of Psychology and Psychopedagogy, 2 (2). http://wwwdialnet.unirioja.es

Iglesias, D. (2002) A model for the analysis of cognitive processes involved in decision making in collective sports. Sports Training Magazine

Iglesias, D. (2003) Knowledge and decision making in team sports: a review from the cognitive perspective. Sports Training Magazine.

Locke, E. A., \& Latham, G. P. (1985). The application of goal setting to sports. Journal of Sport and Exercise Psychology, 7(3), 205-222. https://doi.org/10.1123/jsp.7.3.205

Navelo, R. (2001). Alternative didactic model for the technical-tactical preparation of young volleyball players (Doctoral dissertation, PhD thesis) Higher Institute of Physical Culture "Manuel Fajardo", Havana, Cuba).

Rodionov, P. P., \& Furin, G. G. (1990). Kinetics of nucleophilic substitution reactions of polyfluoroaromatic compounds. Journal of fluorine chemistry, 47(3), 361-434. https://doi.org/10.1016/S0022-1139(00)82395-7

Sainz de la Torre, N. (2010). Psicopedagogía de la Educación Física y el deporte escolar. Deportes.

Sáinz, M., \& López-Sáez, M. (2010). Gender differences in computer attitudes and the choice of technology-related occupations in a sample of secondary students in Spain. Computers \& Education, 54(2), 578-587. https://doi.org/10.1016/j.compedu.2009.09.007

Sánchez, M. E. \& González, M. (2005). General and developmental psychology. Havana: Editorial Sports.

Sánchez, M. E. (2005). Training psychology and sports competition. Havana: Editorial Deportes

Sarmiento, T. (2011). Program of psychological intervention for the training of the focus of attention in athletes of the Venezuelan selection of feminine artistic gymnastics. Master's Thesis. Caracas: UCCFD "Manuel Fajardo

Singh, A., \& Parmar, D. S. (2016). A comparative study of psychological factor among female athletes. International Research Journal of Engineering, IT \& Scientific Research, 2(1), 8-21.

Soler, Y. (2016). Development ofthinking in theinitiation11.

Temprado, J. J. (1991). Les apprentissages décisionnels en EPS. L’apprentissage moteur. Rôle des représentations, $131-155$

Weinberg, D. H., Mortonson, M. J., Eisenstein, D. J., Hirata, C., Riess, A. G., \& Rozo, E. (2013). Observational probes of cosmic acceleration. Physics reports, 530(2), 87-255. https://doi.org/10.1016/j.physrep.2013.05.001 